\title{
El deber de fundamentación del voto de los concejales en el ejercicio de sus funciones
}

\author{
The duty of foundation of the councilor's vote in the exercise of their duties
}

\author{
Jaime Rojas Opazo (iD \\ Abogado, Chile
}

\begin{abstract}
RESUMEN El proceso constitucional que vive Chile abre la puerta para discutir una serie de aspectos de la Administración del Estado, entre ellas, las actuaciones de las autoridades públicas en el marco de la buena administración. Dentro de dichas actuaciones de autoridades encontramos las de los concejales municipales, los cuales deben enmarcar su comportamiento, en forma irrestricta, al ordenamiento administrativo imperante en Chile, motivo por el cual este trabajo aborda un aspecto particular de dicho comportamiento, que dice relación con el sometimiento a la obligación/deber de fundamentar el voto ante materias sometidas a acuerdo de concejo municipal.
\end{abstract}

PALABRAS CLAVE Actos administrativos, concejo municipal, deber de fundamentación, administración pública, autonomía municipal.

ABSTRACT The Constitutional Process that our country is undergoing opens the door to discuss a series of aspects of State Administration, including the actions of public authorities, within the framework of Good Administration. Within these actions of public authorities, we find the Municipal Councilors, who must frame their behavior, in an unrestricted way, to the prevailing administrative order in our country, which is why this paper addresses a particular aspect of such behavior, which is related to the submission to the obligation / duty to substantiate the vote on matters submitted to the Municipal Council Agreement.

KEYWORDS Administrative Acts, municipal council, duty of foundation, public administration, municipal autonomy. 


\section{Introducción}

A raíz del proceso constitucional vigente, iniciado a partir de la suscripción al Acuerdo Por la Paz Social y la Nueva Constitución de noviembre de 2019, y luego de las subsiguientes elecciones plebiscitarias llevadas a cabo el 25 de octubre de 2020, uno de los aspectos que queda sujeto a la revisión del constituyente es el de la organización administrativa del Estado.

Dentro de los órganos que pertenecen a la Administración del Estado encontramos a las municipalidades, cuya estructura orgánica, por una parte, contempla al alcalde, en tanto máxima autoridad y representante, y por otra al Concejo Municipal, órgano fiscalizador del municipio.

Este último órgano interno de la municipalidad posee ciertas características que deben ser estudiadas y analizadas a la luz de una reforma institucional posible en el marco de una nueva Constitución Política de la República. Lo anterior, toda vez que se debe propender a establecer un órgano que no se vuelva un obstaculizador de la función municipal, como ha ocurrido en la actualidad.

Es por ello que el presente trabajo se refiere a la municipalidad en cuanto órgano de la Administración del Estado en tanto la autonomía que le ha conferido, en la teoría, el legislador, para cumplir con sus funciones y tareas, y al Concejo Municipal en particular, en tanto integrante de la estructura orgánica de la municipalidad y la forma en que debiese articular su funcionamiento en el apego al derecho administrativo nacional. Nos referimos particularmente al deber de fundamentar sus decisiones, entendidos los acuerdos de Concejo Municipal como actos administrativos regulados bajo el amparo de lo dispuesto por el artículo 3, inciso siete, de la Ley 19.880 sobre Bases de los Procedimientos Administrativos.

Asimismo, se proponen ciertas modificaciones normativas que pudiesen servir de fundamento para un nuevo entendimiento del actuar del órgano colegiado edilicio.

\section{La autonomía municipal}

Conforme se desprende de la Constitución Política de la República, las municipalidades son corporaciones autónomas de derecho público con personalidad jurídica y patrimonio propio. A partir de lo que expone el jurista Jorge Ortega Gutiérrez, la autonomía que le corresponde a estos órganos de la Administración del Estado puede distinguirse desde las tres dimensiones siguientes.

\section{Dimensión normativa}

Este aspecto de la autonomía municipal se asocia a la potestad autonormativa que le ha sido conferida a los municipios por la Ley 18.695 de Orgánica Constitucional de Municipalidades (LOCM) (Ortega Gutiérrez, 2018: 126). La potestad autonormativa en los aspectos más relevantes de su funcionamiento y de la ordenación comunal, sometida 
solo al ordenamiento jurídico nacional, es claramente un componente esencial de la autonomía de las municipalidades (Ortega Gutiérrez, 2018: 127).

\section{Dimensión institucional}

El elemento o la dimensión institucional de la autonomía municipal dice relación con su conformación y naturaleza (Ortega Gutiérrez, 2018: 127). Esta dimensión supone referirse a dos grandes cuestiones, que son:

- El carácter democrático de la elección de las autoridades comunales.

- La caracterización que le da la Carta Fundamental a los municipios, es decir, que se trate de corporaciones autónomas de derecho público con personalidad jurídica y patrimonio propio.

Que se trate de una corporación responde a que está conformada por el alcalde y el Concejo Municipal; que sean personas jurídicas de derecho público significa que su existencia radica en mandatos constitucionales y no por la voluntad de quienes la integran; que posean patrimonio y personalidad jurídica propia responde a la diferenciación que se hace con el Poder Central, siendo sujetos de derechos y de obligaciones.

\section{Dimensión organizativa}

Esto hace referencia a la forma y a la disposición de los recursos y medios para el cumplimiento de sus fines. La autonomía municipal consta igualmente de tres aspectos fundamentales: la actuación administrativa propiamente tal, la ordenación de sus plantas de persona y la autonomía financiera (Ortega Gutiérrez, 2018: 129).

Importan estos conceptos toda vez que, claramente, está establecido que los municipios, en tanto quienes la conforman como en su funcionamiento, quedan sujetos al cumplimiento y al respeto de los mandatos constitucionales y de las leyes dictadas de conformidad con la Carta Fundamental. Es decir, su autonomía (o potestad de autonormación) no significa que no deban observar los mandatos establecidos por la Constitución Política de la República, motivo por el cual se vuelven aplicables los principios que infunden el derecho público nacional, como a todos los órganos integrantes de la Administración del Estado.

Por esta razón es que no se advierte habilitación adecuada para que los concejales, en ejercicio de sus funciones, no fundamenten las resoluciones a las que arriban, teniendo presente que el Concejo Municipal actúa como cuerpo colegiado y los acuerdos a los que arriba tienen el carácter de acto administrativo.

\section{El Concejo Municipal}

Reza el artículo 118 de la Constitución Política de la República, en su inciso primero, que la administración local de cada comuna estará a cargo del alcalde y del Concejo Municipal. 
El inciso quinto manifiesta que una Ley Orgánica Constitucional determinará funciones y atribuciones de los municipios, así como las materias que serán de competencia del alcalde y también aquellas en que deberá contar con acuerdo del Concejo Municipal.

Esto aparece refrendado en el inciso tercero del artículo 119 de la misma Carta Fundamental, referente a materias específicas. Dicho precepto establece que el Concejo Municipal será un órgano encargado de hacer efectiva la participación de la comunidad local y que ejercerá funciones normativas, resolutivas y fiscalizadoras.

Sobre su naturaleza jurídica, o más bien, su posición jurídica, se puede señalar que la reforma constitucional de 1991 vino a establecer un órgano cuyas atribuciones vienen, por fin, a hacerle un contrapeso al alcalde.

Esto se desprende de lo señalado por el ministro del Interior de la época, Enrique Krauss Rusque, que en la sesión del 20 de junio de 1991, ante las Comisiones Unidas del Congreso Nacional, expresó, al referirse al contenido y al propósito del proyecto de reforma constitucional en cuanto la incorporación del Concejo Municipal y sus funciones, lo siguiente:

La índole normativa y resolutiva del citado organismo está definida por las facultades que se le confiere, en orden a aprobar - a proposición del alcalde- los proyectos del plan comunal de desarrollo y del plan regulador comunal, así como el presupuesto municipal. Igualmente, le compete al Concejo probar los derechos por servicios permisos municipales, permisos y concesiones; acordar, dentro del marco que permita le ley, determinados tributos de carácter local; autorizar las transacciones judiciales y extrajudiciales, y el otorgamiento de concesiones [...] Su carácter fiscalizador lo faculta, a su vez, para ejercer control sobre la ejecución presupuestaria en cumplimiento de los planes municipales, las actuaciones del alcalde y los demás agentes municipales (Biblioteca del Congreso Nacional, 2018: 15-16). ${ }^{1}$

De lo señalado, no se aprecia que a los concejales, como unidades personales, y al Concejo Municipal, como órgano colegiado, se les haya extendido una competencia que signifique la inobservancia de los principios generales del derecho público. En cuanto sus funciones, la LOCM las señala en los artículos 79 a 82.

Siguiendo al actual contralor general de la República y profesor de Derecho Administrativo, Jorge Bermúdez Soto, entre las facultades genéricas que detenta el Concejo Municipal se advierten:

- Recomendar al alcalde desarrollar determinados proyectos o medidas específicas.

- Fiscalizar el cumplimiento de planes y programas, ejecución presupuestaria y actuaciones propias del alcalde.

1. Citado en el Primer Informe de la Comisión de Gobierno, Descentralización y Regionalización y de Constitución, Legislación, Justicia y Reglamento, unidas del Senado, con respecto a la Reforma Constitucional sobre Gobierno y Administración Regional y Provincial y Administración Comunal, Boletín 357-06, del 5 de agosto de 1991. 
- Aprobar la denominación de bienes nacionales de uso público que sean de administración municipal y de los bienes municipales.

- Otorgar aprobación en diversas materias, contempladas por el artículo 65 de la Ley, en materia de planes y programas, y principalmente en materia de recursos financieros (Bermúdez Soto, 2014: 735).

Las distintas facultades que poseen los concejales se concretan en la adopción de acuerdos del Concejo Municipal, los cuales deben ser considerados como actos administrativos, ya que emanan de un órgano de la Administración del Estado en el ejercicio de sus funciones.

\section{Acto administrativo}

Conceptualmente, el acto administrativo puede verse desde distintas posiciones: una doctrinaria, una legal y una jurisprudencial.

Desde la doctrina, una de las definiciones de mayor factura es la que entrega el profesor Juan Carlos Ferrada (2011: 252), quien los conceptualiza como:

Actos jurídicos emanados de un órgano de la Administración del Estado, que poseen ciertas cualidades y características que los hacen, en cierto sentido, excepcionales dentro del ordenamiento jurídico. Esa excepcionalidad les permite, entre otras cosas, gozar de una presunción de legalidad o validez desde su inicio, lo que lleva aparejado su ejecutividad, ejecutoriedad y aun su ejecución forzada en ciertos casos (artículo 3 y 51 de la Ley 19.880 sobre Bases de los Procedimientos Administrativo).

Atendida esta definición, se puede ir trazando la idea de que el acto administrativo tiene un fin protector del interés público, y que, dada su naturaleza, goza de cierta excepcionalidad en el ordenamiento jurídico toda vez que sus características y cualidades lo hacen acreedor de cierta validez desde su inicio.

No obstante, lo anterior debe indicar que el acto administrativo aparece definido por el artículo 3, inciso segundo, de la Ley de Bases Generales de los Procedimientos Administrativos 19.880, el que reza:

Para efectos de esta ley se entenderá por acto administrativo las decisiones formales que emitan los órganos de la Administración del Estado en las cuales se contienen declaraciones de voluntad, realizadas en el ejercicio de una potestad pública (Ley 19.880, 2003: artículo 3, inciso segundo).

El profesor Enrique Silva Cimma (1959: 26) sostenía que el acto administrativo es la declaración de voluntad general o individual de un órgano administrativo emitida en función de una potestad o competencia administrativa por la cual se deciden o emiten juicios sobre derechos, deberes e intereses de las entidades administrativas o de los particulares con respecto a estas. 
Importa en este punto agregar que, dentro de la tipología de actos administrativos que contempla la ley están los acuerdos, como se desprende del inciso séptimo del precepto indicado previamente. Sobre lo anterior, se debe poner atención a lo señalado por la Contraloría General de la República, ente que ha dispuesto que:

Al efecto, cabe señalar que el concepto amplio de acto administrativo que contempla el artículo 3 de la Ley 19.880 incluye a las declaraciones de juicio que realicen los órganos de la Administración en el ejercicio de sus competencias, entendiendo por tales, en el contexto de ese cuerpo legal, las que tienen por objeto informar acerca de las materias que la ley ha colocado dentro de la respectiva esfera de atribuciones, con miras a la resolución del procedimiento administrativo que corresponda y que se expresan mediante dictámenes (Dictamen 45.336, 2008).

El mismo entre contralor ha señalado que:

Precisado lo anterior, es dable manifestar que, de acuerdo con el criterio establecido en los dictámenes 45.336 de 2008; 79.639 de 2011; y 4.309 de 2012, el inciso sexto del artículo 3 de la citada Ley 19.880 incluye, dentro del concepto de acto administrativo, a las declaraciones de juicio que realicen los órganos de la Administración en el ejercicio de sus competencias, entendiendo por tales, en el contexto de ese cuerpo legal, las que tienen por objeto expresar el punto de vista de dichos órganos acerca de la materia sobre la cual se ha requerido su opinión (Dictamen 7.620).

Así las cosas, conforme lo indicado y transcrito, es fácil advertir que tanto el legislador como la interpretación del órgano contralor han dado tratamiento de acto administrativo al acuerdo emanado de órgano pluripersonal, tipología de órgano de la Administración del Estado que se condice con el Concejo Municipal.

Asimismo, tanto la doctrina como la jurisprudencia administrativa han estimado que son actos administrativos aquellos que emanan de los órganos de la Administración del Estado en el ejercicio de sus funciones, toda vez que tienen por objeto expresar el punto de vista sobre la materia que ha requerido de su pronunciamiento.

\section{El principio de juridicidad}

Teniendo presente lo indicado, una de las materias que es importante destacar es la relacionada con los principios que fundan el derecho público nacional, que afectan y regulan directamente la actividad administrativa del Estado.

En términos generales, se pueden indicar los principios de dignidad humana, juridicidad, tutela judicial, garantía patrimonial, tutela de derechos fundamentales, subsidiariedad del Estado, servicialidad del Estado, probidad administrativa, publicidad, responsabilidad patrimonial del Estado y control de la Administración.

Importa, en lo particular, el principio de juridicidad, el cual es uno de los más importantes del derecho público y sobre el cual se erige su base. Este principio se encuentra consagrado por la Constitución Política de la República en sus artículos 6 y 7. 
Se torna relevante destacar que, conforme a este principio, ningún órgano de la Administración del Estado puede actuar sin someter su comportamiento a la Constitución y a las normas dictadas conforme con ella, así como ninguna persona ni autoridad puede atribuirse facultades o derechos más allá de lo constitucional y de lo legalmente establecido.

A propósito, Jorge Ortega Gutiérrez (2018:133) señala que «el principio de juridicidad exige una actuación de los órganos del Estado sujeta al ordenamiento jurídico, esto es, su sumisión a la ley en su sentido lato». Rolando Pantoja Bauzá (2000), por su parte, agrega que, «en cuanto a la superficie regulada, el principio de la juridicidad abarca el ser y el actuar de la Administración del Estado, su organización y su actuación jurídica». Asimismo, Gabriel Celis Danzinger (2019: 36) dice que «el principio de juridicidad de la Administración es el respeto y la sujeción integral al ordenamiento jurídico por parte de los órganos de la Administración del Estado».

La Contraloría General de la República ha señalado, a propósito de este principio, que se trata de aquel:

En virtud del cual todos los organismos del Estado se encuentran sometidos al ordenamiento jurídico, debiendo adecuar su obrar a la preceptiva vigente, y sus decisiones tener una motivación y un fundamento racional, por lo que no cabe ejercer arbitrariamente sus potestades, sino en conformidad con las disposiciones en vigor (Dictamen $54.026,2010)$.

El respeto por este principio, en cuanto a concejales se trata, ha sido señalado por la Contraloría General de la República de la siguiente forma:

Finalmente, cabe hacer presente que, en el ejercicio de sus atribuciones, los concejales deben respetar el principio de juridicidad, que lleva implícita la racionalidad y la proporcionalidad en el actuar de los órganos de la Administración, evitando todo abuso o exceso acorde con lo dispuesto en los artículos 6 y 7 de la Constitución en relación con el artículo 2 de la Ley 18.575, Orgánica Constitucional de Bases Generales de la Administración del Estado (aplica criterio contenido en el dictamen 41.100 de 2001; dictamen 38.037, 2008).

De conformidad con lo expresado, queda de manifiesto que, al Concejo Municipal, en su naturaleza de órgano de la Administración del Estado, le corresponde el pleno y total respeto por el principio de juridicidad, cuestión por la cual debe adecuar su conducta a las normas legales vigentes.

\section{El deber de fundamentación y motivación de los actos administrativos: El acuerdo de Concejo Municipal}

Sin duda, se trata de una de las materias que mayor importancia reviste para el estudio del derecho administrativo nacional. En ese sentido, cabe traer a colación lo indicado por Baltazar Morales Espinoza (2018: 19), quien señala: 
Nuestro ordenamiento jurídico no contiene una descripción y un desarrollo de los elementos que integran la noción de acto administrativo. La doctrina nacional, con matices, ha abordado el tema, señalando para efectos sistemáticos y de academia los elementos que deben concurrir. A saber, son: la competencia e investidura, la causa, el objeto, el fin y las formalidades.

Jurisprudencialmente, se ha señalado que:

Constituye uno de los elementos del acto administrativo la motivación de él, pues, a través de ella, se exteriorizan las razones que han llevado a la Administración a dictarlo, exigencia que se impone en virtud del principio de legalidad. En efecto, en nuestro ordenamiento jurídico, la Ley 19.880, que establece las Bases de los Procedimientos Administrativos que rigen los actos de los órganos de la Administración del Estado, consagra los principios de transparencia y publicidad en cuanto permite y promueve el conocimiento del contenido y los fundamentos de las decisiones que adopten los órganos de la Administración del Estado [...] Es así como el artículo 11, inciso segundo, del referido texto legal, previene la obligación de motivar, en el mismo acto administrativo, la decisión, los hechos y los fundamentos de derecho que afecten los derechos o las prerrogativas de las personas. A su turno, también el artículo 41, inciso cuarto, del aludido texto legal, dispone que «las resoluciones que contenga la decisión serán fundadas». Proceder que, por lo demás, se hace enteramente exigible por mandato del artículo 8 de la Constitución Política de la República (Sentencia de la Corte Suprema de Justicia, rol 3598-2017, 2017: considerando quinto).

Así, la sentencia indicada agrega que:

La exigencia de motivación de los actos administrativos, atendido los contornos de la cuestión puesta en conocimiento de la judicatura, se relaciona directamente con el ejercicio de las potestades con las que está revestida la Administración. En efecto, en doctrina se distingue entre el ejercicio de facultades regladas y facultades discrecionales. En las primeras, toda la actuación previa al nacimiento de un determinado acto administrativo se encuentra prevista y determinada en la ley, por lo que la autoridad debe ceñirse estrictamente a ella tanto al verificar los supuestos de hecho como en el procedimiento que determina la decisión, que está igualmente regulada en relación con la situación fáctica que la origina. En cambio, en el ejercicio de las facultades discrecionales, la Administración goza de cierto ámbito de libertad al momento de adoptar la decisión. Interesa destacar que, en este último caso, indudablemente concurren etapas regladas, toda vez que debe existir norma expresa que entregue a un órgano determinado la libertad para decidir ante precisos supuestos de hecho.

En este aspecto, Luis Cordero Vega (2015: 83), citando a Menéndez, señala:

En términos simples, podemos decir que la potestad discrecional se dará en los casos en que el legislador le confiere a la Administración un espacio de autodeterminación, un margen o libertad de decisión para elegir entre varias alternativas o soluciones posibles. La adopción de los actos que se dicte en ejercicio de una potestad de esa naturaleza se basará, entonces, en criterios no predeterminados por la norma que con- 
cede el margen de decisión, sino en criterios que quedan a la libre consideración de la Administración. ${ }^{2}$

Con respecto a esta sentencia, el profesor José Francisco García García ${ }^{3}$ realizó un importante comentario siguiendo la siguiente lógica: Primero, sostiene que la motivación del acto administrativo, por mandato de los principios constitucionales y legales de publicidad y transparencia, implica la exposición clara y concreta de los motivos del acto administrativo (considerando noveno). Enseguida, manifiesta que la motivación del acto administrativo, entendido como una "resolución fundada», implica un examen riguroso de las razones que lo motivan; lo que lleva, en consecuencia, siempre a «analizar concretamente las razones esgrimidas por la Administración» (considerando doce). Finalmente, señala que la motivación debe incluir una relación circunstanciada de los fundamentos de la decisión, indispensables para evaluar su razonabilidad y proporcionalidad.

Agrega García García que, en efecto, para la corte, el control de razonabilidad de la decisión importa:

Que el acto administrativo en que se funda debe basarse en motivos que deben explicitarse (más allá de una mera cita de normas y hechos) mediante una relación circunstanciada de los fundamentos de la decisión de manera que se acredite la racionalidad intrínseca, es decir, coherencia con los hechos determinantes y con el fin público que ha de perseguirse. ${ }^{4}$

Teniendo como referencia de suma importancia la sentencia cuyas partes se han transcrito, es deber indicar que la Excelentísima Corte Suprema ha venido sosteniendo insistentemente que la motivación del acto administrativo es un elemento de su esencia. Así, por ejemplo, la sentencia rol 58.971-2016, caratulada «Junta de Vigilancia del Río Huasco/SERNAGEOMIN», en su considerando doce manifestó la falta de apego al principio de imparcialidad del artículo 11 de la Ley 19.880 en cuanto se dictó un acto administrativo infundado, motivo por el cual se configuraba la infracción al artículo 19, número 2, de la Constitución Política de la República, que consagra la garantía de igualdad en la ley.

Ahora bien, es importante tener presente que, desde hace largo tiempo, se ha entendido que los actos administrativos deben contener la exposición de los fundamentos que han permitido su dictación. Así, desde tiempos remotos, la Contraloría General de la República ha defendido que:

El ejercicio de las facultades administrativas que compete a los jefes superiores de los organismos públicos se materializa a través de la dictación de actos administrati-

2. Véase Sentencia de la Corte Suprema de Justicia, rol 3598-2017, 2017: considerando sexto.

3. José Francisco García García, «Corte Suprema y motivación del acto administrativo (a propósito de la sentencia rectora Universidad de Aysén)», 10 de octubre de 2017, disponible en https://bit.ly/314UuF.

4. Véase nota anterior. 
vos o resoluciones que se encuentran sujetas a un procedimiento preestablecido que permite que el acto se baste a sí mismo y cuyo cumplimiento es esencial para la validez de dicho instrumento, como indicación en su texto de las normas legales y reglamentarias que le sirven de fundamento, las consideraciones de hecho que hacen aplicable la medida adoptada (Dictamen 33.006, 1984).

A propósito de este pronunciamiento, los profesores Fermandois y Barahona (2003: 87) expresan que:

La doctrina ha estimado que este dictamen, vinculante para todos los órganos de la Administración por obra de la Ley 10.336, orgánica de ese órgano contralor, vino ha imponer una exigencia generalizada de motivación a todo acto público. Soto Kloss subraya que este dictamen «es el pronunciamiento clave de esta jurisprudencia repetido sin variaciones de modo frecuente».

Además, Fermandois y Barahona (2003: 87) señalan que: «Dice Sayagués que los elementos esenciales del acto administrativo son un «órgano competente, con voluntad administrativa, contenido, motivos, finalidad, forma y procedimiento». Y de paso agregan que:

Vergara Blanco, siguiendo a la doctrina española, distingue entre lo que son los «motivos» y lo que es la «motivación». El motivo es el elemento que conforma al acto administrativo, es el que nunca podrá ser ni arbitrario ni ilegal; «motivación» sería, entonces, la expresión de aquellos motivos en el propio acto cuando la ley lo obligue. Por tanto, la «motivación» podría estar o no expresa en el acto si la ley lo señala. Por ello, tenemos actos o resoluciones «fundadas» $\mathrm{y}$ «no-fundadas». Por tanto, lo que siempre deberá existir es la habilitación legal al órgano administrador y los motivos para que el acto pueda concretizarse dentro del ordenamiento. La expresión de dichos motivos será, al final, una decisión del legislador (Fermandois Vöhringer y Barahona González, 2003: 88; el destacado es nuestro).

Los académicos referidos, citando al actual ministro del Tribunal Constitucional y expresidente de dicho órgano, Iván Aróstica Maldonado, señalan, a propósito del motivo del acto administrativo, que:

Debe existir y estar jurídicamente bien calificado. Que el motivo o motivación de hecho exista significa que debe ser real y efectivo, vale decir, que sea concreto y cierto. De darse la situación contraria, se tipificaría la falsedad del motivo, lo que ameritaría para demandar la nulidad del acto administrativo (Fermandois Vöhringer y Barahona González, 2003; el destacado es nuestro).

Lo señalado indica que existe una manifestación tanto legal como doctrinaria y jurisprudencial en defender la obligatoriedad de la fundamentación y la motivación de todo acto administrativo, incorporando las consideraciones de hecho y de derechos que permiten su dictación. 
Es por ello que, considerando la posición tanto jurisprudencial y doctrinaria, un acuerdo de Concejo Municipal, que tiene la calidad jurídica de acto administrativo en razón de lo dispuesto por el artículo 3, inciso séptimo, de la Ley 19.880, no está exento de cumplir con dicha obligación/deber de fundamentación y motivación, razón por la cual es de toda lógica sostener que corresponde aplicar la legislación vigente para que dicha obligación/deber se cumpla en forma irrestricta.

No obstante, es importante indicar que se torna de relevancia legislar sobre la materia, en el sentido de expresar férreamente el deber que recae sobre los concejales de fundar su posición ante las materias que sean objeto de consideración del Concejo Municipal, toda vez que, lamentablemente, se produce una cierta clase de vacío legal que debe ser llenado mediante legislación al respecto.

Peor aún, nos encontramos con ciertas interpretaciones, alejadas del espíritu del legislador, que dan cabida a la arbitrariedad en el comportamiento de los ediles, produciendo así una esfera de amparo al desconocimiento e inaplicación de las normas sobre fundamentación de los actos administrativos.

No podemos sino discrepar de lo interpretado por Marcelo Villagrán Abarzúa, quien cree que a los concejales no se les puede exigir que expliquen las razones para emitir su voto. Esto basado en una supuesta libertad que ellos tendrían en el ejercicio de su función. Al efecto, señala:

Un ejemplo de la libertad en el ejercicio del cargo es que no compete a autoridad alguna el exigirles que expliquen las razones por las cuales emiten sus votos en un determinado sentido, ni tampoco es posible definir la legalidad de un acuerdo del Concejo en base al examen de las actas cuando se hayan consignado esas razones, ya que son expresión de la libertad de esas autoridades para votar en un determinado sentido, como lo estableció la propia Contraloría General de la República (Villagrán Abarzúa, 2015: 71).

Dicha interpretación implicaría atribuir a los concejales potestades en su condición personal, olvidando que el Concejo Municipal actúa en tanto órgano colegiado, por lo que las resoluciones que emite (acuerdos) deben ser vistos como actos administrativos, razón por la cual quedan sometidos a la obligación/deber de estar fundados y motivados.

Por otra parte, sostener que existe tan amplia libertad en el ejercicio de la función de concejal implicaría poner en entredicho la satisfacción del interés general por sobre los intereses particulares. Dicha libertad, que defiende Villagrán Abarzúa, podría significar dar pie a la arbitrariedad en las decisiones de autoridades electas. En la práctica ello es así. Concejales, por demostrar su oposición al alcalde, votan en contra de proyectos que van en directo beneficio de la Municipalidad basados en cuestiones meramente caprichosas, arbitrarias, personales, incluso de odiosidad, lo que está lejos de poder ser amparado por la libertad en el ejercicio de una función. Un ejemplo lo podemos situar en torno a la aprobación o al rechazo de obras públicas licitadas por un municipio, con 
respecto a las cuales deben someter a acuerdo de Concejo la suscripción del correspondiente contrato.

En este punto, la Contraloría General de la República ha señalado que la función de los concejales se remite exclusivamente a aprobar o rechazar la suscripción del contrato. Ahora bien, ambas posiciones debiesen estar fundadas al menos en cuestiones que digan relación con el interés público. Principalmente, dicha cuestión debiese ser férreamente defendida en el caso de los rechazos para que no se produzcan situaciones de arbitrariedad absoluta.

La Contraloría Regional de O’Higgins expresó al efecto que:

Finalmente, y sin perjuicio de lo expuesto, conviene aclarar que, como ya se señaló, la participación de los concejales en los procesos licitatorios se reduce, conforme al artículo 65, letra j, de la Ley 18.695, a aprobar o rechazar la propuesta presentada por el alcalde, para lo cual puede exigir a esa autoridad todos los antecedentes necesarios al efecto, sin que la normativa atingente contemple otra instancia en que se requiera la intervención de tales personeros en el desarrollo de dichos certámenes (Oficio de la Contraloría Regional de O'Higgins E45466/2020: 4-5).

Si se hace revisión de ciertos Concejos Municipales (Ilustre Municipalidad de Nancagua, 2020), ${ }^{5}$ se puede advertir que los concejales muchas veces rechazan la propuesta del alcalde en razón de cuestiones «técnicas», que corresponde evaluar al Municipio y sus unidades. Todo esto, además de argumentar en base a cuestiones de índole personal y alejadas de las materias que dicen relación con la normativa vigente.

En este punto, se vuelve de toda relevancia traer a colación lo dispuesto por la Contraloría General de la República sobre la materia:

En relación con tal acuerdo, es menester recordar que, en concordancia con el artículo 3, inciso séptimo, de la Ley 19.880 - que establece Bases de los Procedimientos Administrativos que rigen los actos de los Órganos de la Administración del Estado-, la decisión que adopte el Concejo debe llevarse a efecto a través de la correspondiente resolución de la autoridad alcaldicia, constituyendo así un acto administrativo que, como tal, debe ser debidamente fundado en los términos previstos en los artículos 11 y 41 de ese texto legal (Dictamen 48.512, 2012).

Agrega el órgano fiscalizador:

5. Así, por ejemplo, en Sesión Ordinaria 126 del Honorable Concejo Municipal de Nancagua, celebrada el 27 de mayo de 2020, se puede observar cómo ciertos concejales rechazan la propuesta del alcalde motivados por cuestiones aparentemente técnicas, cuya apreciación corresponde al Municipio en seguimiento a lo dispuesto por el ente contralor y en relación con el artículo 65, letra j, de la Ley de Municipalidades. Además, de observarse, cuestiones de índole personal. Al efecto, uno de los ediles nancagüinos, en dicha oportunidad, conforme señala el acta de Concejo, rechazó la propuesta en razón de no querer participación con posibles testaferros. Si ello no implica una actuación motivada por cuestiones personales y, por tanto, arbitraria, al menos, se aleja del espíritu que persigue la ley en cuanto dar valor a los argumentos que sustentan un acto administrativo. 
Siendo ello así, por una parte, el Concejo no puede rechazar la propuesta alcaldicia de adjudicación por motivos ajenos a los contemplados en las bases correspondientes, y por otra, el establecimiento de alguna restricción o causal para rechazar una oferta necesariamente debe haberse determinado previamente por el municipio en las mismas (Dictamen 48.512, 2012).

Finalmente, el ente contralor sostiene:

Así, tanto la resolución que materialice el acuerdo del Concejo tendiente a rechazar una determinada propuesta de adjudicación de una licitación regida por la citada Ley 19.886 como la decisión que adopte la autoridad alcaldicia en orden a declarar desierto el respectivo proceso - como aconteció en la especie- deben encontrarse debidamente fundamentados en la normativa regulatoria de él y explicitarse en el acto administrativo pertinente (aplica criterio contenido en el dictamen 33.622, de 2008; Dictamen 48.512, 2012).

Así las cosas, y tomando principalmente lo señalado por Fermandois y Barahona, la motivación y fundamentación de los actos administrativos no puede quedar al arbitrio de los integrantes de un órgano administrativo, como es el Concejo Municipal.

Por tanto, se vuelve una necesidad imperiosa defender fuertemente la idea de que la votación de los concejales, en las materias sometidas a acuerdo de Concejo Municipal, debe estar fundada y no expresar meramente su aprobación o rechazo. Y, además, que la toma de posición debe estar sustentada en la protección del interés público y no en caprichos o cuestiones que pudieren ser consideradas arbitrarias, ya que ello implicaría alejarse del cumplimiento de los principios que fundan el derecho administrativo chileno.

El Tribunal de Contratación Pública ha recogido el guante en esta materia, tomando una posición potente y clara:

Los argumentos esgrimidos por los concejales para oponerse a la adjudicación de la propuesta efectuada por el alcalde, según consta de las mencionadas actas del Concejo, carecen de base legal, ya que no estaban contemplados como requisitos a exigir a los oferentes o no se acreditan de manera alguna o, simplemente, no se concuerda con la calificación que efectuó la Comisión de Adjudicación, que analiza y otorga los puntajes conforme a los estándares fijados en las bases, como se ha indicado precedentemente, versus la opinión de algunos concejales sin respaldo suficiente, lo que constituye una arbitrariedad (Sentencia del Tribunal de Contratación Pública rol 92-2011, 2012: considerando vigésimo).

El mismo Tribunal, en otra oportunidad (sentencia del Tribunal de Contratación Pública rol 15-2010, 2010: considerandos 18 y 19), concluyó que los decretos alcaldicios deben contener los adecuados y correspondientes fundamentos legales para adjudicar licitaciones públicas, no siendo aceptable consideraciones de carácter general.

Asimismo, podemos encontrar sentencias de las altas magistraturas nacionales tendientes a sostener este criterio de obligatoriedad de la fundamentación del voto de los 
concejales. A modo de ejemplo, la Excelentísima Corte de Apelaciones de Santiago manifestó en su oportunidad:

Que, consecuentemente, como acertadamente lo ha resuelto el tribunal a quo, si bien es efectivo que correspondía al Concejo Municipal de la comuna de Punta Arenas pronunciarse acerca de la propuesta de adjudicación del alcalde, tal pronunciamiento debía cumplir con las normas referidas, debiendo estarse siempre a aquellos principios que rigen los procedimientos administrativos de contratación, destacándose el principio de estricta sujeción a las bases de licitación. No pueden los concejales rechazar sin más la propuesta de adjudicación, pues ello vulnera todo el sistema que rige la contratación pública: tal rechazo debe estar fundado en hechos objetivos, debiendo actuar dichos funcionarios con imparcialidad y, por cierto, siempre respetando las bases de licitación lo que, en la especie, no ocurrió. Luego, tal decisión vició también el decreto alcaldicio 3.379 de 25 de septiembre de 2009 dictado por el señor alcalde de la comuna de Punta Arenas (Sentencia de la Corte de Apelaciones de Santiago rol 4855-2010, 2010: considerando cuarto).

\section{Propuesta de reformas constitucional y legal}

Una manera que vislumbramos para solucionar este vacío la encontramos en introducir una reforma a la LOCM en lo que dice relación con el texto del artículo 79, literal b. Actualmente, este precepto indica:

Al Concejo le corresponderá: [...] b) Pronunciarse sobre las materias que enumera el artículo 65 de esta ley. Los concejales presentes en la votación respectiva deberán expresar su voluntad, favorable o adversa, con respecto a las materias sometidas a aprobación del Concejo, a menos que les asista algún motivo o causa para inhabilitarse o abstenerse de emitir su voto, debiendo dejarse constancia de ello en el acta respectiva (Ley 18.695, 2006: artículo 79, literal b).

Por nuestra parte, abogamos por incorporar los siguientes incisos:

Cada concejal deberá fundamentar y motivar su voto en base a cuestiones o materias que digan relación con la protección del interés público, con tal de fundar la aprobación, rechazo o abstención con que concurra a la materia sometida a acuerdo de Concejo Municipal, cuestión que deberá quedar plasmada en la correspondiente acta que se levante al efecto.

La no observancia de dicha obligación por algún concejal deberá quedar expresada en la correspondiente acta que se levante al efecto. En este sentido, se entenderá que existe una infracción al deber de probidad administrativa, de conformidad con lo dispuesto por el artículo 62, número 8, de la Ley 18.575 Orgánica Constitucional de Bases Generales de la Administración del Estado.

Lo anterior dice relación con darle uniformidad al ordenamiento jurídico, en razón del principio de unidad explicado por el profesor Eduardo Cordero Quinzacara (2009: 
31), ${ }^{6}$ y de dejar expresa constancia de la obligatoriedad de fundamentación de las decisiones que adopten los concejales en tanto autoridades públicas, las que deben respetar los principios y reglas que regulan nuestro derecho.

Ello no resultaría en lo absoluto útil si no se incorporara una Reforma Constitucional en el Capítulo XIV «Gobierno y Administración Interior del Estado» en el apartado de Administración Comunal, particularmente el artículo 119.

En efecto, el inciso final del artículo dispone:

La ley orgánica de municipalidades determinará las normas sobre organización y funcionamiento del Concejo y las materias en que la consulta del alcalde al Concejo será obligatoria y aquellas en que necesariamente se requerirá el acuerdo de este. En todo caso, será necesario dicho acuerdo para la aprobación del plan comunal de desarrollo, del presupuesto municipal y de los proyectos de inversión respectivos (Constitución Política de la República, 2005: artículo 119, inciso final).

A dicho precepto, creemos, debiese introducirse el siguiente párrafo:

El acuerdo de Concejo Municipal, al que se hace alusión, deberá estar debidamente fundado, entendiéndose para ello la expresión y la constancia de las circunstancias y los argumentos que esgrime cada edil para adoptar una decisión, sea esta de aprobación o de rechazo, frente a la materia sometida a su conocimiento. Más aún, en caso de pesar sobre un concejal causal de inhabilidad para participar del acuerdo, debe dejar establecidas las razones que fundan dicha imposibilidad.

Lo indicado no solo vendría a dar sentido a las exigencias que la propia Carta Fundamental explicita sobre la función pública, emanadas principalmente de lo preceptuado por los artículos 6 y 7 , en cuanto consagran el denominado principio de juridicidad, sino que tiene un impacto desde un punto de vista de proteger el principio de probidad y transparencia, así como el de publicidad de los actos públicos emanados ambos del artículo 8 de la Constitución Política de la República, que expresa:

El ejercicio de las funciones públicas obliga a sus titulares a dar estricto cumplimiento al principio de probidad en todas sus actuaciones

Son públicos los actos y resoluciones de los órganos del Estado, así como sus fundamentos y los procedimientos que utilicen (Constitución Política de la República, 2005: artículo 8, incisos primero y segundo, primera parte).

Por tanto, se explica de sobremanera la importancia que tiene elevar la exigencia del funcionamiento del Concejo Municipal en tanto órgano de la Administración del Estado, ya que sus decisiones no pueden ser, por ningún motivo, arbitrarias, y de acuerdo

6. Señala Cordero Quinzacara: «En efecto, la Constitución garantiza la unidad del ordenamiento jurídico en la medida que es fundamento último de validez de todas las normas que lo integran. Sin embargo, la unidad no solo se limita al tema de la validez de las normas, sino también a la unidad que debe darse a ellas al momento de ser interpretadas. Dicho en otros términos, debe existir también unidad en el sentido y alcance de las normas». 
con ciertos criterios vigentes, pareciere ser que se está dando lugar a que ello ocurra, lo que se vuelve inaceptable conforme a las demandas actuales sobre rectitud en el ejercicio de las funciones públicas, de las cuales no pueden estar ajenas incluso aquellas entidades que responden a ciertos criterios políticos.

\section{Conclusiones}

Conforme a la doctrina y a la jurisprudencia, nos inclinamos por sostener que, de aplicarse estrictamente la normativa legal imperante para las actuaciones administrativas, el comportamiento y la ejecución de funciones por parte de los concejales, en tanto partícipes e integrantes del Concejo Municipal, órgano colegiado conformante de la estructura interna municipal, debiese apegarse al cumplimiento del principio de fundamentación y motivación de los actos administrativos.

Ello, no solo en seguimiento y cumplimiento de los principios y reglas que fundan el derecho administrativo nacional, sino que también en armonía con el derecho a una buena administración, la cual supone un ejercicio de funcionarios e instituciones de forma imparcial, ecuánime, alejada de la discrecionalidad o en el marco de una discrecionalidad regulada, diligenciada.

Lo anterior también dice relación con la necesidad de reconducir a los órganos del Estado hacia una evaluación positiva por parte de la ciudadanía, en el marco del combate de la corrupción y la crisis de confianza hacia la institucionalidad, punto culmine que encontramos en el estallido social del 18 de octubre de 2019. En ese sentido, es dable sostener que decisiones motivadas y fundadas, no meramente caprichosas o arbitrarias, contribuyen con dar mayor transparencia a los procesos en pro del resguardo del interés público.

Sin embargo, mientras subsistan ciertas interpretaciones en línea contraria, que implicarían desconocer la aplicación estricta de las normas del derecho público nacional en ciertas actuaciones de las indicadas autoridades públicas y que no se condicen en lo absoluto con las dimensiones de autonomía que el legislador ha entregado a los municipios, se debe proponer un trabajo en que los órganos competentes aboguen por sostener la idea amplia de fundamentación de toda actuación administrativa con tal de proscribir las arbitrariedades y regular la discrecionalidad.

No obstante, proponer reforma constitucional y legal, en el sentido indicado por este trabajo, cuyo fin sería introducir expresamente la sujeción del actuar edilicio a la obligación/deber de fundamentar y motivar sus actuaciones, con el objeto de erradicar completamente las posibilidades de aparición de arbitrariedades y de defensa de intereses particulares por sobre el interés general parece razonable con tal de darle un sentido de uniformidad al ordenamiento nacional, entendiendo, además, que ello permite fortalecer los principios de transparencia, probidad y de publicidad de los actos públicos. 


\section{Referencias}

Bermúdez Soto, Jorge (2014). Derecho administrativo general. Santiago: Thomson Reuters.

Biblioteca del Congreso Nacional (2018). Historia de la Ley 19.097: Modifica la constitución política de la Republica en materia de gobiernos regionales y administración comunal. Disponible en https://bit.ly/2TQskuC.

Celis Danzinger, Gabriel (2019). Los principios constitucionales del derecho administrativo. Santiago: Hammurabi.

Cordero Quinzacara, Eduardo (2009). «Los principios y reglas que estructuran el ordenamiento jurídico chileno». Ius et Praxis, 15 (2): 11-49. Disponible en https://bit. ly/3GxIRIH.

Cordero Vega, Luis (2015). Lecciones de derecho administrativo. 2. ${ }^{\text {a }}$ ed. Santiago: Thomson Reuters.

Fermandois Vöhringer, Arturo y Jorge Barahona González (2003). «La inexistencia de los hechos que fundamentan un acto administrativo, ¿Constituye un vicio de nulidad?». Revista de Derecho Universidad (Finis Terrae), 7 (7): 79-103. Disponible en https://bit.ly/3jFRapO.

FErrada Bórquez, Juan Carlos (2011). «Los procesos administrativos en el Derecho chileno». Revista de Derecho (Pontificia Universidad Católica de Valparaíso), 36 (1): 251-257. Disponible en https://bit.ly/3yB5Z3D.

Ilustre Municipalidad de Nancagua, Secretaría Municipal (2020). Acta 126 de la sesión ordinaria del honorable Concejo Municipal de Nancagua del 27 de mayo de 2020. Disponible en https://bit.ly/3CeeOCr.

Morales Espinoza, Baltazar (2018). Actos Administrativos. Santiago: DER.

Ortega GutiérRez, Jorge (2018). La autonomía municipal en el marco de la organización del Estado de Chile. Santiago: Hammurabi.

Pantoja Bauzá, Rolando (200o) «El principio de la juridicidad». Revista de Derecho Público, 62: 156-168. Disponible en https://bit.ly/3aRtElD

Silva Cimma, Enrique (1959). Derecho administrativo. Tomo II. Santiago: Universitaria. Villagrán Abarzúa, Marcelo (2015). Manual de Derecho Municipal. Santiago: RIL.

\section{Sobre el autor}

Jaime Rojas Opazo es abogado y licenciado por Ciencias Jurídicas de la Universidad Nacional Andrés Bello. Además, actualmente cursa el Magíster en Derecho Penal y Procesal Penal que imparte la Universidad Nacional Andrés Bello. Su correo electrónico es jrojasopazo@gmail.com. (D) https://orcid.org/oooo-0oo1-7401-9255. 
